\title{
Notes on the vocalizations of Speckle-breasted Wren (Thryothorus sclateri)
}

Peter Boesman

In the following we briefly analyze and compare voice of the different races of Specklebreasted Wren (Thryothorus sclateri). We also try to quantify the extent of any vocal differences using the criteria proposed by Tobias et al. (2010), as a support for taxonomic review. We have made use of sound recordings available on-line from Xeno Canto (XC).

Song of all races is a lively synchronous duet. Call is quite diagnostic, a peculiar rising trilled note.

An overview of vocalizations per race, illustrated with sonograms:

\section{paucimaculatus}

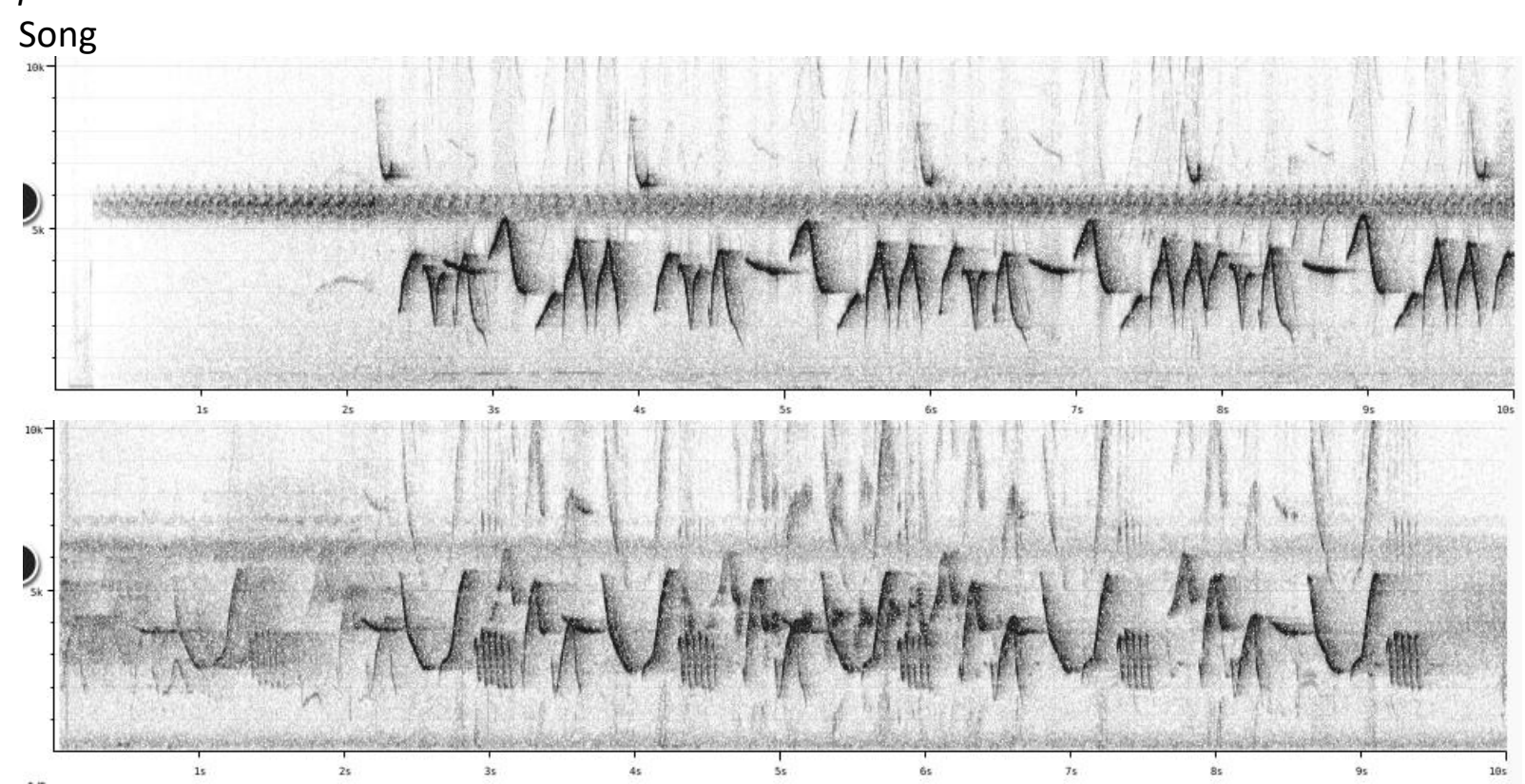

Call
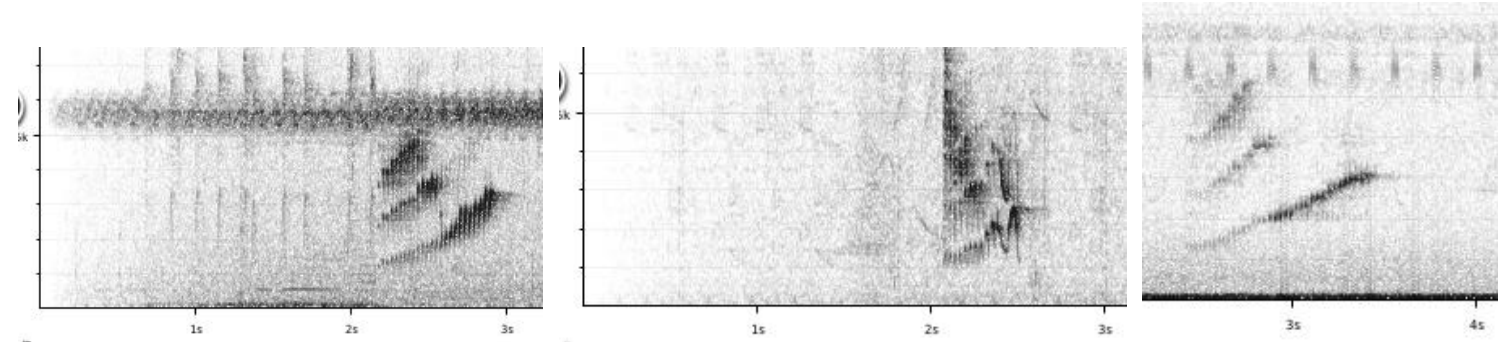


\section{HANDBOOK OF THE \\ AlRD Allue WORLD ORNITHOLOGICAL NOTES}

\section{nominate}

Song
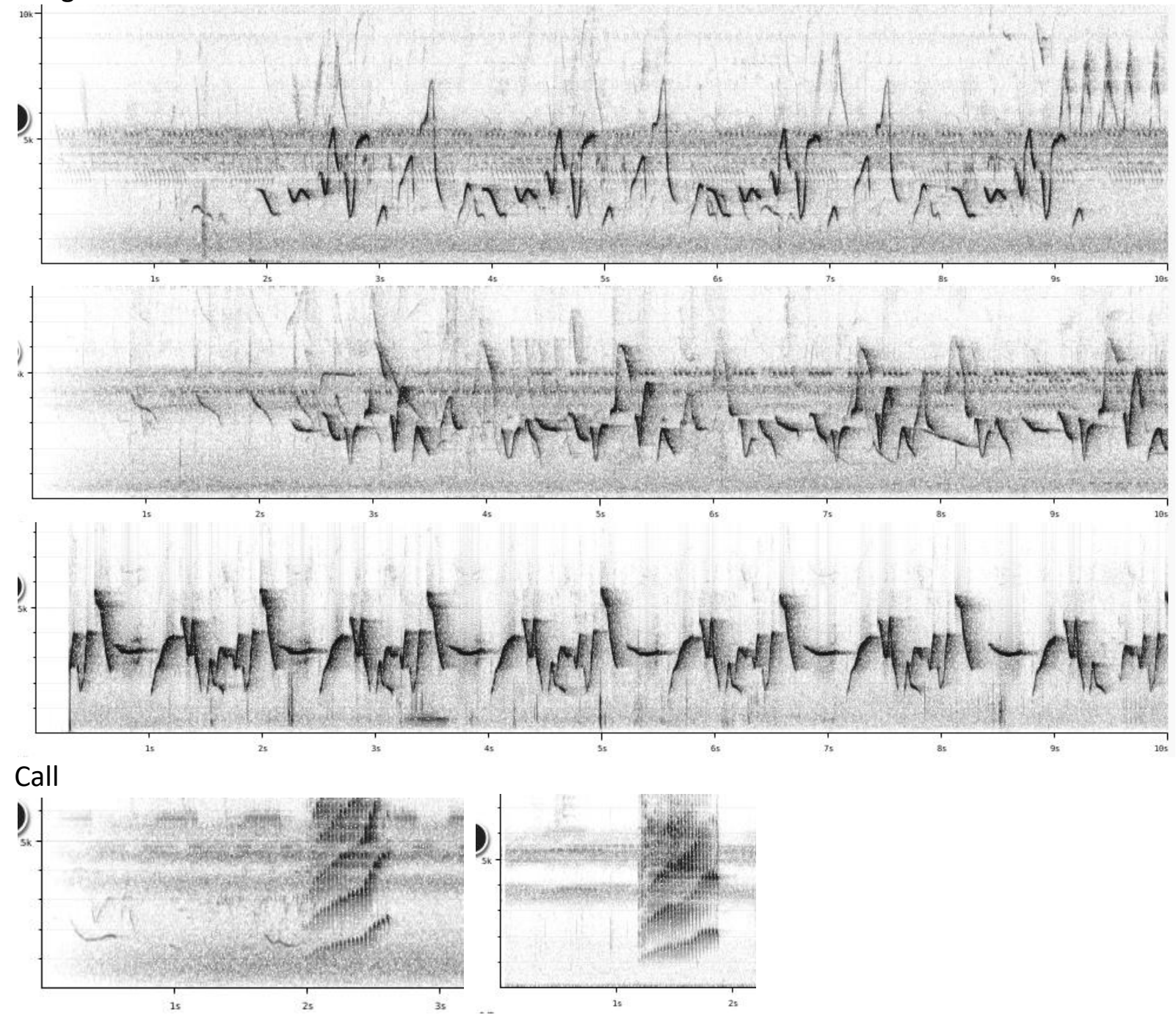

colombianus

Song
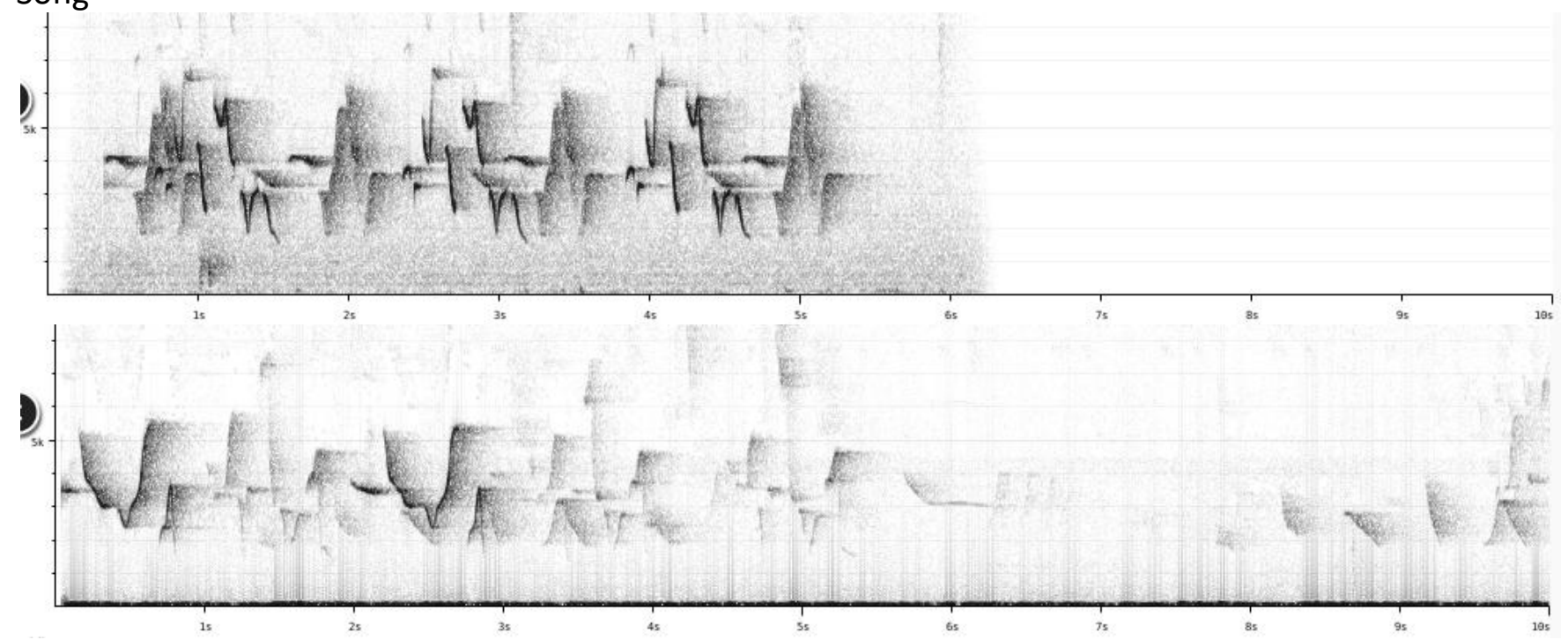


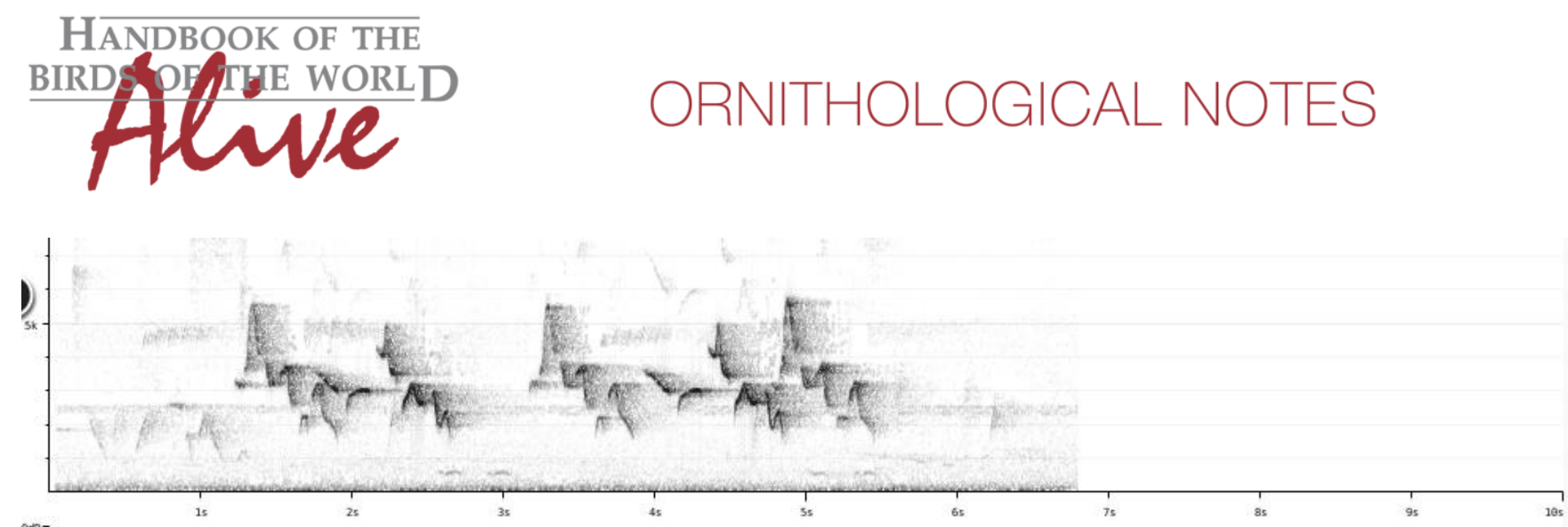

Call

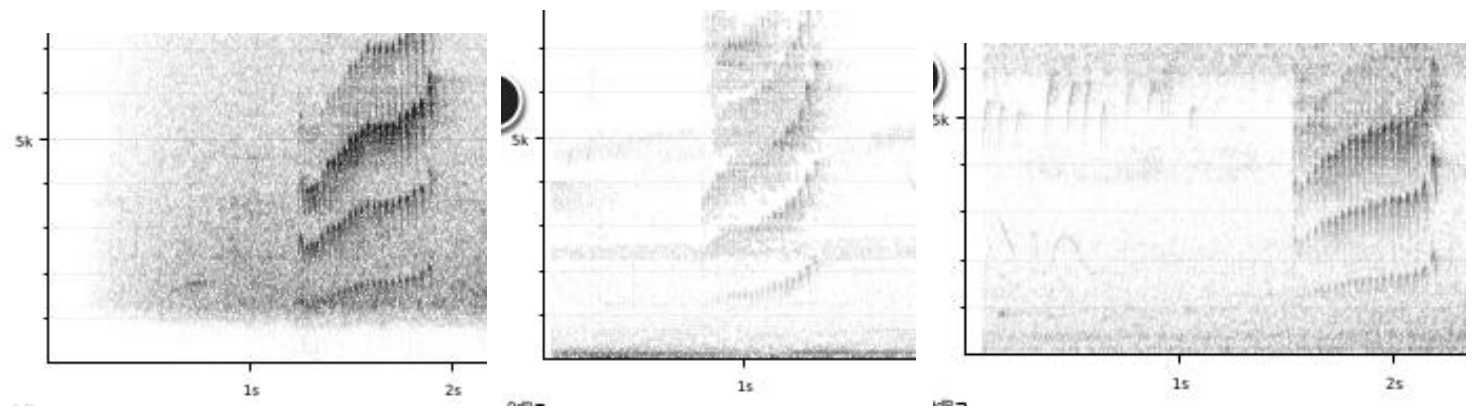

Duet songs of all races are quite variable, and don't show obvious differences. Period duration of the repeated phrase is ranging from c. $1.5 \mathrm{~s}$ to $2.1 \mathrm{~s}$. Frequency range of notes in all races also quite similar (paucimaculatus sometimes throwing in very high-pitched notes, but not always). A more in depth comparison with many more samples would be needed to find out whether there are true vocal differences in duet song (e.g. paucimaculatus may use more overslurred notes), but differences can be expected to be quite subtle at most.

On the other hand, there is a notable difference in the rising burry call note: paucimaculatus has a very distinct sonogram, the latter part of the call is becoming a pure whistle and as a result harmonics disappear. The base frequency also reaches higher frequencies: typically reaching c. $3 \mathrm{kHz}$ vs. $2 \mathrm{kHz}$ in the other 2 races. While this is not the primary vocalization, this is quite a striking difference, for which a score 2 could be allowed.

This note was finalized on 15th April 2016, using sound recordings available on-line at that moment. We would like to thank in particular the many sound recordists who placed their recordings for this species on XC.

\section{References}

Tobias, J.A., Seddon, N., Spottiswoode, C.N., Pilgrim, J.D., Fishpool, L.D.C. \& Collar, N.J. (2010). Quantitative criteria for species delimitation. Ibis 152(4): 724-746.

\section{Recommended citation}

Boesman, P. (2016). Notes on the vocalizations of Speckle-breasted Wren (Thryothorus sclateri). HBW Alive Ornithological Note 291. In: Handbook of the Birds of the World Alive. Lynx Edicions, Barcelona. (retrieved from http://www.hbw.com/node/1251737 on 12 October 2016). 